\title{
Small-group, interactive education and the effect on asthma control by children and their families
}

\author{
Wade T.A. Watson MD MEd, Cathy Gillespie MN, Nicola Thomas BN, Shauna E. Filuk BN, \\ Judy McColm RN, Michelle P. Piwniuk RRT, Allan B. Becker MD
}

Previously published at www.cmaj.ca on Aug. 17, 2009.

$\infty \infty$

See related commentary by Cates

\section{ABSTRACT}

Background: Effective approaches to education about asthma need to be identified. We evaluated the impact on asthma control by children and their caregivers of an intervention involving small-group, interactive education about asthma.

Methods: We randomly assigned children who visited an emergency department for an exacerbation of asthma ( $n=$ 398) to either of 2 groups. Children assigned to the control group followed the usual care recommended by their primary care physician. Those assigned to the intervention group participated in a small-group, interactive program of education about asthma. We examined changes in the number of visits to the emergency department during the year after the intervention.

Results: During the year after enrolment, children in the intervention group made significantly fewer visits to the emergency department ( 0.45 visits per child) compared with those in the control group ( 0.75 visits per child) $(p=$ 0.004). The likelihood of a child in the intervention group requiring emergency care was reduced by $38 \%$ (relative risk [RR] 0.62, 95\% confidence interval $\mathrm{Cl} 0.48-0.81, p=$ 0.004 ). Fewer courses of oral corticosteroids ( 0.63 per child) were required by children in the intervention group than by those in the control group ( 0.85 per child) $(p=$ 0.006 ). We observed significant improvements in the symptom domain of the questionnaire on pediatric asthma quality-of-life $(p=0.03)$ and the activity domain of the questionnaire on caregivers' quality of life $(p=0.05)$. Parents of children in the intervention group missed less work because of their child's asthma after participating in the educational program $(p=0.04)$. No impact on hospital admissions was observed.

Interpretation: Education about asthma, especially in a small-group, interactive format, improved clinically important outcomes and overall care of children with asthma.

Une version française de ce résumé est disponible à l'adresse www.cmaj.ca/cgi/content/full/cmaj.080947/DC1 
the material. They can learn from each other in a supportive, nonjudgmental environment. They can both give and receive peer-oriented feedback. They can practise skills that can be applied later in real-life situations. Learners retain and transfer knowledge more effectively when they are able to practise what they have learned. ${ }^{18}$ For children with asthma and their families, such a model would help facilitate memory retention and a higher comfort level with future decisions related to management of asthma.

We conducted a randomized controlled trial to evaluate the impact on asthma control of an intervention involving smallgroup, interactive education of children with asthma and their caregivers.

\section{Methods}

\section{Participants}

We conducted the study at the Children's Hospital of Winnipeg, located in a moderate-sized urban setting in the Canadian prairie province of Manitoba. The hospital's emergency department had 40000 visits per year, 3500 of which were due to acute asthma. We used emergency department records to identify children who had a diagnosis of asthma. We used letter and telephone-based follow-up to contact families of the children to invite them to participate in the study. Children were eligible if they were aged 3-16 years, had physician-diagnosed asthma and had required a visit to the emergency department for acute asthma during the recruitment phase. We excluded children who had other serious chronic illnesses, including respiratory illnesses other than asthma. We also excluded families for whom a significant language barrier existed. We did not offer incentives for participation. During the recruitment phase, we performed screening by contacting families by telephone after their visits to the emergency department. We closed recruitment after we reached our target for enrolment $(n=400)$. We randomly assigned each child to either the control group or intervention group on their first visit to the study site..

\section{Study protocol}

We assessed participating children and their families at a hospital-based site called the Children's Asthma Education Centre. We collected the following data: a focused asthma history, height and weight, medications used, responses to the Pediatric Asthma Quality of Life Questionnaire ${ }^{19}$ for children aged 7 years or older, responses to the Pediatric Asthma Caregiver's Quality of Life Questionnaire, ${ }^{20}$ the Classroom Productivity and Caregiver Work Productivity questionnaires related to asthma (adapted from an existing questionnaire on allergy-related impairment), ${ }^{21,22}$ and number of visits made to the emergency department during the year before enrolment. We performed spirometry for children aged 7 years and older using the Vitalograph-Compact Spirometer (Vitalograph Ltd., Buckingham, United Kingdom).

We randomly assigned families to either of 2 groups. Children assigned to the control group followed the usual care recommended by their primary care physician and were given a booklet with basic information on asthma (Appendix 1, available at www.cmaj.ca/cgi/content/full/cmaj.080947
/DC2). The booklet had been developed previously for children admitted to hospital for an exacerbation of asthma. Children assigned to the intervention group participated in our program of education about asthma along with their usual care. At the time of our study, usual care did not include oneon-one education on asthma by an educator. We randomized the assignment of families based on a computer-generated allocation in blocks of 10. Because of the nature of the study, blinding was not possible. We assessed participants in both study groups at 12 months after enrolment using the same tools as in our initial assessment.

Our study was approved by the Faculty Committee on the Use of Human Subjects in Research, based at the University of Manitoba. Funding was provided by Manitoba Health, the Winnipeg Children's Hospital Foundation and unrestricted educational grants from AstraZeneca, Merck Frosst and GlaxoSmithKline.

\section{Educational program}

The Children's Asthma Education Centre developed a 4-week educational program using materials containing core content and supplemental resources that were based on recommendations from the Canadian Asthma Consensus Statement ${ }^{23}$ on education about asthma. These materials included a programspecific booklet for families enrolled in the educational program (Appendix 2, available at www.cmaj.ca/cgi/content/full /cmaj.080947/DC2) and personalized mailings to reinforce the program's key messages (Appendix 3, available at www.cmaj .ca/cgi/content/full/cmaj.080947/DC2). Pamphlets on asthmarelated topics, which were produced by the centre for a reader comprehension level of grade 8 or below, were also used.

The educational program was targeted to either the parent or the child, or both, depending on the age of the child, with core content adapted for age level as appropriate. The educational content was the same for each group. For children aged 3-6 years, parents were the participants in the intervention. For children aged 7-11 years, both parents and children participated in the education sessions, but did so in separate groups. For adolescents (aged 12-16 years), only the adolescent attended the program (Figure 1). The educational program was designed for a group of 6-8 participant families or adolescents and addressed different topics of importance in the management of asthma. The program was delivered by a nurse-educator experienced in asthma management and a respiratory therapist who were among the first nationally certified asthma educators in Canada. Groups met for about 1.5 hours per week over 4 weeks to discuss 4 themed topics (Appendix 4, available at www.cmaj.ca/cgi/content/full/cmaj.080947/DC2).

An important part of the program was the promotion of small-group interaction for children and their families. Parents actively discussed their successes and failures in the management of their child's asthma. Children and their families learned from each other as well as from the educator. The educator acted as a resource and guide for the discussion. In addition, families were sent personalized mailings at 2, 4, 6 and 12 months after enrolment that reinforced key educational messages using the program's main topics (Appendix 3, available at www.cmaj.ca/cgi/content/full/cmaj.080947/DC2). 


\section{Outcome measures}

The primary outcome measure was change in the number of visits to the emergency department during the year after the intervention. Secondary outcome measures included the impact of asthma-related education on the number of admissions to hospital, quality of life, use of oral corticosteroid therapy for exacerbations of asthma, productivity in the workplace and pulmonary function. We calculated a sample size of 400 (200 in each group) to provide a power of $80 \%$ with an $\alpha$ of 0.05 or less.

\section{Statistical analysis}

We performed an intention-to-treat analysis for number of emergency department visits. We analyzed results using repeated-measures analysis of variance, including the primary outcome measure. In addition, we performed a Poisson regression analysis to determine relative risks (RRs) for visits to the emergency department, hospital admissions and use of oral corticosteroids. For secondary outcomes, we used $t$ tests, Fisher exact test and $\chi^{2}$ analysis. We considered a $p$ value of 0.05 or less to be significant. Our primary hypothesis was that our intervention would result in a $25 \%$ reduction in visits to the emergency department by participants in the intervention group.

\section{Results}

\section{Participants}

Over a 30-month period, we identified 2901 eligible children from emergency department records. The recruitment and flow of participants through the study is shown in Figure 2. We sent letters to all of the families of eligible children to invite them to participate and followed up by telephone. Of the 1120 families who responded, $41 \%$ declined to participate,
$11 \%$ were unsure whether their child had asthma and $11 \%$ expressed interest in education but could not commit to it at that time. Of the 415 families who agreed to participate, $17 \mathrm{did}$ not arrive for the initial assessment and 398 were enrolled. We carried out enrolment from June 1997 to January 2000.

The demographic characteristics of participants are shown in Table 1. In both the intervention and control groups, most children had made 1 visit to the emergency department in the year before enrolment (77\% in each group). The groups also had similar proportions of participants who had made 2 visits (15\% v. $12 \%)$ and who had made 3 or more visits $(6.5 \% \mathrm{v}$. $5.9 \%)$. Use of inhaled corticosteroids, either intermittently or regularly, was not statistically different between the 2 groups. The distribution across socio-economic levels among the families in our study concorded generally with that of families seen in our emergency department. Ethnic background (accorded by self-identified maternal heritage) was similar in both groups. The groups also had similar proportions of livein smokers and of families that allowed smoking inside the home. No significant differences existed in number of visits made to the emergency department, number of hospital admissions, pulmonary function or oral corticosteroid use during the year before enrolment. The level of attendance at the program's classes was $65 \%$ in the preschooler group, $80 \%$ in the school-aged group and $79 \%$ in the adolescent group.

\section{Primary outcome}

The number of visits to the emergency department decreased in both the control and intervention groups (Table 2), but we observed a significantly greater reduction in the intervention group $(p=0.0037)$. Compared with the control group, the intervention group had a lower likelihood of requiring emergency care. (RR $0.62,95 \%$ confidence interval [CI] $0.48-$ $0.81, p=0.0004)$.

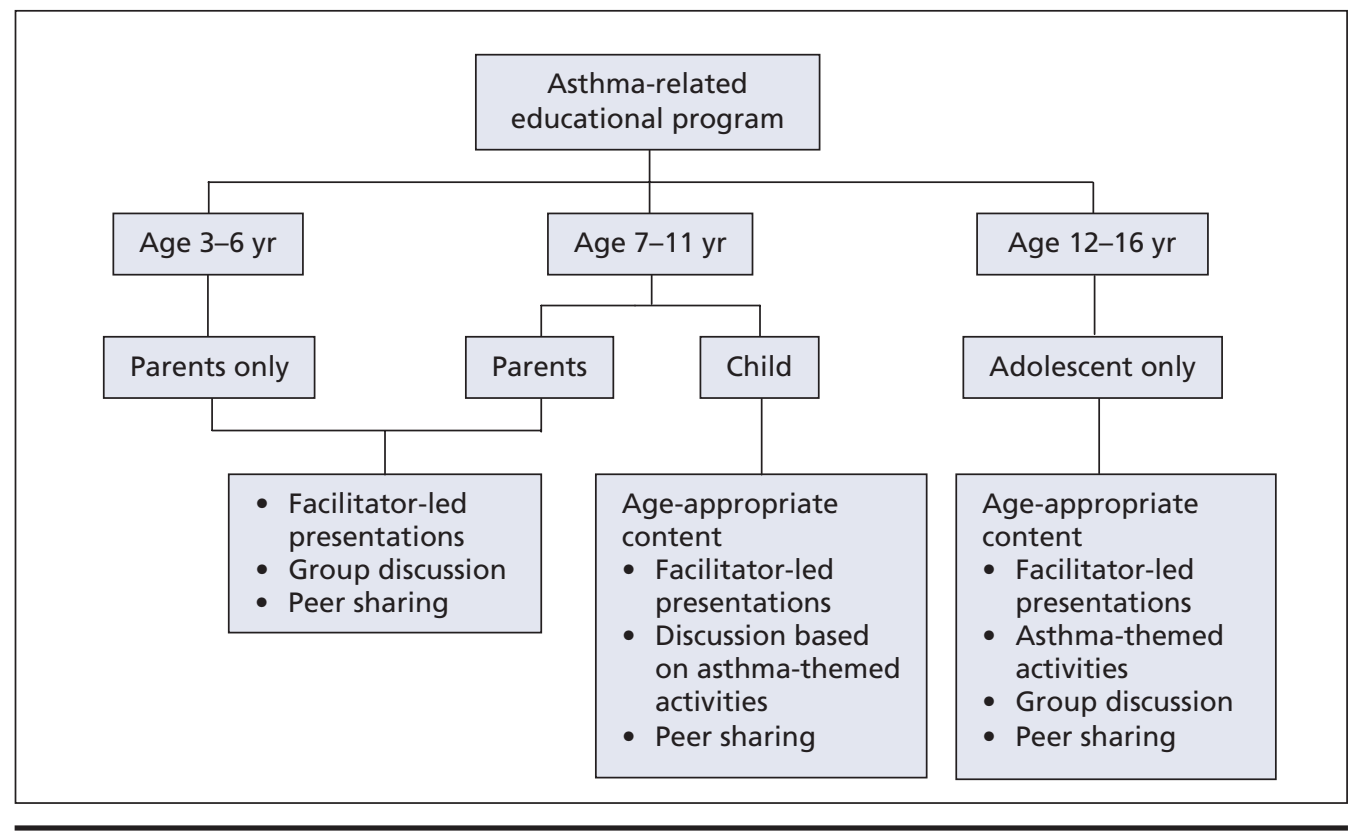

Figure 1: Outline of asthma-related education program by age group. For program content, see Appendix 4, available at www.cmaj.ca/cgi/content/full/cmaj.080947/DC2. 


\section{Secondary outcomes}

The number of admissions to hospital was low in both groups. Each group showed a significant drop in admissions but we observed no significant difference between the groups (Table 2). Compared with the control group, the intervention group used fewer courses of oral corticosteroid therapy per patient during the year after enrolment $(p=0.006)$. The likelihood of a child in the intervention group requiring oral corticosteroids was reduced by $36 \%$ (RR $0.64,95 \%$ CI 0.50 $0.82, p=0.001$ ).

For children who were able to undergo spirometry testing

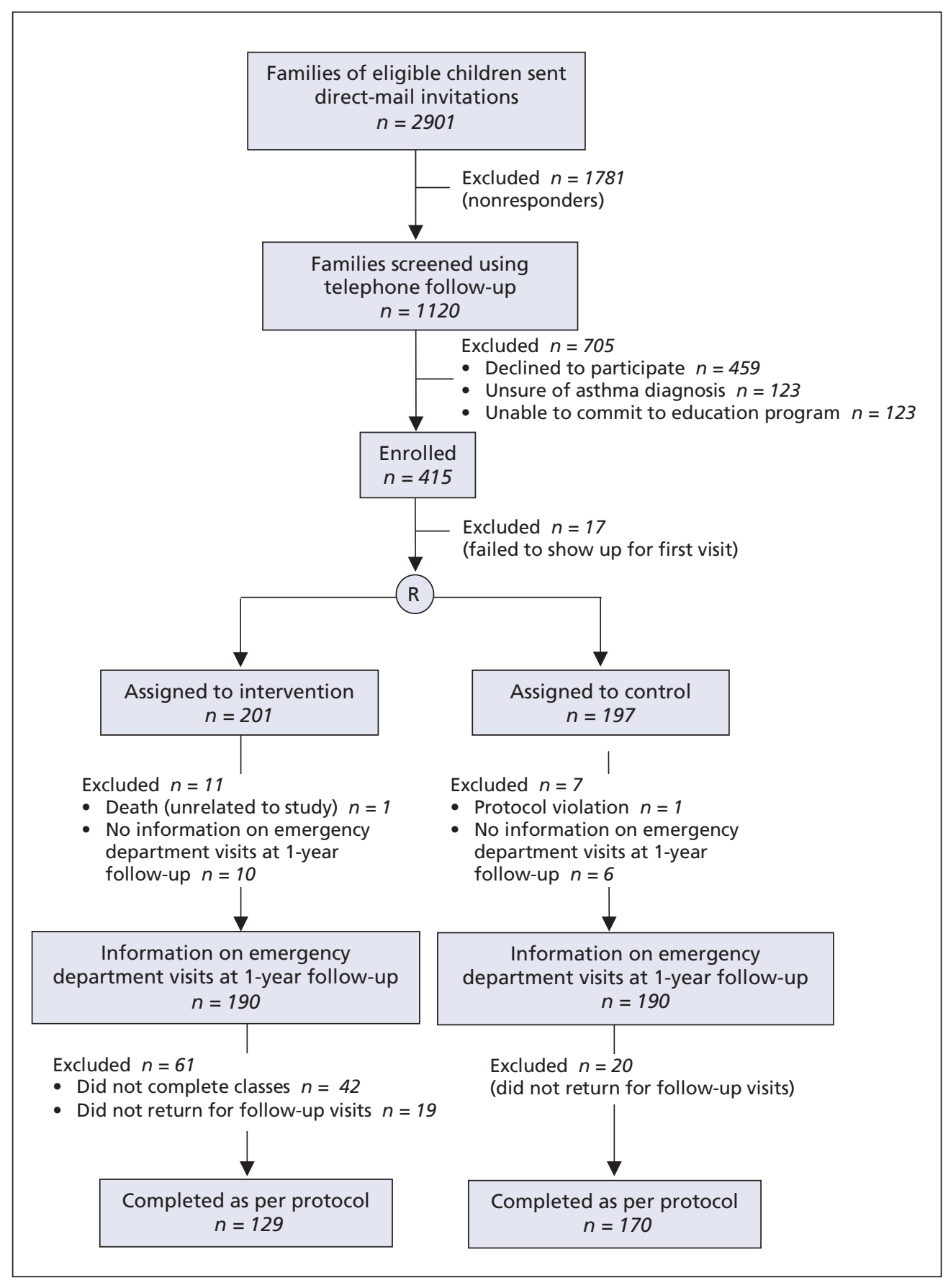

Figure 2: Flow of participants through the trial. $\mathrm{R}=$ randomized. (control $n=79$, intervention $n=70$ at study completion), we analyzed results using percent-predicted forced expiratory volume in 1 second $\left(\mathrm{FEV}_{1}\right)$. We found no difference in the percent-predicted $\mathrm{FEV}_{1}$ between groups. Asthma education had a significant impact on workplace productivity for primary caregivers who worked outside of the home (control $n=$ 79 , intervention $n=65$ ). Primary caregivers in the intervention group missed significantly less work than those in the control group in the month before the final assessment at the end of the follow-up period $(p=0.04)$.

In both the control and intervention groups, we observed significant improvement in total scores on the Pediatric Asthma Quality of Life Questionnaire during the year after enrolment. In the symptom domain, a clinically important statistical difference (a change of 0.5 unit per question) was observed in favour of the intervention group $(p=0.03)$. Caregivers in both groups showed significant improvement in scores on the Pediatric Asthma Caregiver's Quality of Life Questionnaire during the year after enrolment. This improvement was greater in the intervention group, but not significantly so $(p=0.10)$. In the domain of activities, we observed both a statistical $(p=$ 0.05 ) and clinically important difference in the intervention group compared with the control group.

At completion of the study, $35 \%$ of the homes of participants had smokers living in them, with no significant difference between the intervention and control groups. Among families in the control group, $30 \%$ continued to allow smoking in the home, as compared with $18 \%$ of those in the intervention group $(p=0.019)$.

\section{Interpretation}

The program of education about asthma provided by the Children's Asthma Education Centre significantly reduced the need for hospital-based emergency services among participating children with 
asthma. Asthma-specific quality of life improved in the domains of the children's assessments of their symptoms and in caregivers' scores. Primary caregivers of participating children lost fewer workplace hours. This reduction implied that the asthma was under better control. It was consistent with studies showing that the number of workdays lost by caregivers was correlated highly with level of control of asthma. ${ }^{24}$ Fewer courses of oral corticosteroid therapy were required by participants during the year after enrolment.

Our study was prospective and randomized, with an appropriate control group that had no in-depth intervention. Our use of a control group was particularly important because, as we expected, a regression toward the mean occurred wherein participants in the control group made significantly fewer visits to the emergency department for acute asthma during the year after enrolment. Nevertheless, we observed a significantly greater reduction in visits among children in the intervention group.

Small-group interaction was the major learning tool of our educational intervention. This tool provided parents and children with opportunities to share their experiences with asthma, solve problems together and provide support to one another while allowing role-modelling to occur. From a theoretic perspective, smallgroup interaction is a highly desirable tool for enhancing education. ${ }^{16-18}$ Other investigators have observed a reduction in the severity of asthma only when knowledge was imparted in an interactive setting. ${ }^{25}$ Interactive learning may also increase the confidence of families in managing asthma, although we recognize that this method of learning will not be suitable for all people or all situations.

Individual studies undertaken through 2004 have shown that education about asthma improves knowledge about asthma, ${ }^{7,26-34}$ although it does not guarantee an improvement in other outcomes. Some studies have suggested a relation between educational intervention and improvement in attitudes or self-management skills. ${ }^{7,15,34}$

${ }^{39}$ Educational interventions may be connected to improvements in quality of life $\mathrm{e}^{40-}$ ${ }^{42}$ and peak expiratory flow rates. ${ }^{8,43}$

The most important outcomes of providing education about asthma involve changes in the use of health care services. Post-education outcomes that have been identified by researchers include reductions in the numbers of visits to emergency departments, admissions to hospitals and unscheduled visits to physicians, and in costs related to health care. . $10,26,44-47^{-1}$ From 2005 onward, an increasing number of randomized control trials have been performed. ${ }^{48-55}$ Some have focused on schools with children as the target learners ${ }^{50-52}$ or included a multifaceted approach with education as one component. ${ }^{50,53,54}$ The results generally have been positive, showing increases in knowledge, fewer symptoms and fewer absences from school. Although studies that involved multifaceted programs showed fewer visits to emergency departments, it is difficult to conclude with certainty that such outcomes are attributable solely to the educational component in these studies. ${ }^{53,54}$ Our program remains unique in that it incorporates the principles of small-group learning for children or for both children and their parents and includes only an educational intervention.

\section{Limitations and strengths}

Our study has limitations. It did not have sufficient power
Table 1: Baseline characteristics of participants in a randomized controlled trial of a small-group, interactive education program about asthma

\begin{tabular}{|c|c|c|}
\hline \multirow[b]{2}{*}{ Characteristic } & \multicolumn{2}{|c|}{ Trial group } \\
\hline & $\begin{array}{l}\text { Intervention } \\
\quad n=201\end{array}$ & $\begin{array}{l}\text { Control } \\
n=197\end{array}$ \\
\hline Age, yr, mean (SD) & $7.4(3.4)$ & $7.4(3.3)$ \\
\hline Sex, ratio of boys to girls & $1.75: 1$ & $2.34: 1$ \\
\hline Height, cm, mean (SD) & $127.8(20.2)$ & $121.8(20.6)$ \\
\hline Weight, kg, mean (SD) & $30.9(16.6)$ & $28.3(14.1)$ \\
\hline \multicolumn{3}{|l|}{ Ethnic background $\dagger$} \\
\hline White & 68 & 67 \\
\hline Aboriginal & 6 & 9 \\
\hline Other (Asian, South Asian) & 26 & 24 \\
\hline \multicolumn{3}{|l|}{ Socio-economic quintile } \\
\hline 1 (lowest income) & 18 & 25 \\
\hline 2 & 33 & 19 \\
\hline 3 & 15 & 20 \\
\hline 4 & 19 & 18 \\
\hline 5 (highest income) & 14 & 18 \\
\hline Homes with smokers & 46 & 40 \\
\hline Homes allowing visitors to smoke & 29 & 31 \\
\hline $\begin{array}{l}\text { Visits to emergency department in } \\
\text { previous year, per child, mean (SEM) }\end{array}$ & $1.37(0.07)$ & $1.34(0.07)$ \\
\hline $\begin{array}{l}\text { Hospitalizations in previous year, per } \\
\text { child, mean (SEM) }\end{array}$ & $0.21(0.02)$ & $0.18(0.02)$ \\
\hline $\mathrm{FEV}_{1}, \%$ predicted,$\neq$ mean $(\mathrm{SEM})$ & $87(1.04)$ & $88(0.97)$ \\
\hline Using inhaled $\beta$-agonist at enrolment & 99.0 & 98.8 \\
\hline $\begin{array}{l}\text { Using inhaled corticosteroid at } \\
\text { enrolment }\end{array}$ & 91.2 & 84.0 \\
\hline $\begin{array}{l}\text { Oral corticosteroid use in previous year, } \\
\text { courses per child, mean (SEM) }\end{array}$ & $1.53(0.08)$ & $1.33(0.07)$ \\
\hline $\begin{array}{l}\text { Workplace productivity of primary } \\
\text { caregiver, } \S \text { mean (SEM) }\end{array}$ & $18.7(2.4)$ & $12.9(2.2)$ \\
\hline
\end{tabular}

Note: $\mathrm{FEV}_{1}=$ forced expiratory volume in 1 second, SD = standard deviation, $\mathrm{SEM}=$ standard error of mean.

*Unless stated otherwise.

†According to participant-reported maternal heritage.

‡Based on age and height. Control $n=94$, intervention $n=99$.

$\S$ Calculated based on percentage of total work hours missed in the month before assessment. Control $n=80$, intervention $n=65$. 
to assess the differences in outcomes between different age groups. We encountered difficulties in recruiting participants. Only $37 \%$ of the families with whom we had direct contact were enrolled. We may not have reached the population most in need of education, despite the representation of a broad variety of different socio-economic backgrounds among the families of enrolled participants. Families who participated in our program were highly motivated. It would be difficult to assess the impact of our intervention

\section{Table 2: Primary and secondary outcomes in the year after enrolment among participants in a randomized controlled trial of a small-group, interactive education program about asthma}

\begin{tabular}{|c|c|c|c|c|}
\hline \multirow[b]{2}{*}{ Outcome } & \multicolumn{2}{|c|}{ Trial group } & \multirow[b]{2}{*}{$\operatorname{RR}(95 \% \mathrm{Cl})$} & \multirow[b]{2}{*}{$p$ value } \\
\hline & Intervention & Control & & \\
\hline \multicolumn{5}{|l|}{ Primary } \\
\hline $\begin{array}{l}\text { Visits to emergency } \\
\text { department, per child* }\end{array}$ & $n=190$ & $n=190$ & & \\
\hline Mean (SEM) & $0.45(0.07)$ & $0.75(0.07)$ & $0.62(0.48-0.81)$ & $0.004 \ddagger$ \\
\hline $\begin{array}{l}\text { Change from } \\
\text { baseline }\end{array}$ & -0.92 & -0.59 & & \\
\hline \multicolumn{5}{|l|}{ Secondary } \\
\hline $\begin{array}{l}\text { Admissions to hospital, } \\
\text { per child* }\end{array}$ & $n=190$ & $n=190$ & & \\
\hline Mean (SEM) & $0.05(0.02)$ & $0.06(0.02)$ & $0.90(0.38-2.1)$ & $0.80 \ddagger$ \\
\hline $\begin{array}{l}\text { Change from } \\
\text { baseline }\end{array}$ & -0.16 & -0.12 & & \\
\hline $\begin{array}{l}\text { Oral corticosteroid use, } \\
\text { courses per child }\end{array}$ & $n=129$ & $n=170$ & & \\
\hline Mean (SEM) & $0.63(0.08)$ & $0.85(0.07)$ & $0.64(0.50-0.82)$ & $<0.001 \neq$ \\
\hline $\begin{array}{l}\text { Change from } \\
\text { baseline }\end{array}$ & -0.90 & -0.48 & & \\
\hline $\mathrm{FEV}_{1}, \%$ predicted & $n=70$ & $n=79$ & & \\
\hline Mean (SEM) & $90(1.02)$ & $88(0.97)$ & & $0.36 \S$ \\
\hline $\begin{array}{l}\text { Change from } \\
\text { baseline }\end{array}$ & 2 & 0 & & \\
\hline $\begin{array}{l}\text { Workplace productivity } \\
\text { of caregivert }\end{array}$ & $n=65$ & $n=79$ & & \\
\hline Mean (SEM) & $0.8(2.4)$ & $5.0(2.3)$ & & $0.04 \S$ \\
\hline $\begin{array}{l}\text { Change from } \\
\text { baseline }\end{array}$ & -17.9 & -7.9 & & \\
\hline Homes with smokers & $n=129$ & $n=170$ & & \\
\hline$\%$ & 34.6 & 34.5 & & $0.99 * *$ \\
\hline $\begin{array}{l}\text { Change from } \\
\text { baseline }\end{array}$ & -11.2 & -5.7 & & \\
\hline $\begin{array}{l}\text { Homes allowing visitors } \\
\text { to smoke }\end{array}$ & $n=129$ & $n=170$ & & \\
\hline$\%$ & 18 & 30 & & $0.019 * *$ \\
\hline $\begin{array}{l}\text { Change from } \\
\text { baseline }\end{array}$ & -10.8 & -1.1 & & \\
\hline
\end{tabular}

Note: $\mathrm{FEV}_{1}=$ forced expiratory volume in 1 second, RR = relative risk, SEM = standard error of mean. * Results were based on an intention-to-treat analysis.

†Calculated based on percentage of total work hours missed during the month before assessment. $\ddagger$ Results were based on Poisson regression analysis.

$\S$ Results were based on repeated measures analysis of variance.

$* *$ Results were based on $\chi^{2}$ test. in a less motivated group. Whereas this difficulty is true for any educational program, we uniquely used interactive strategies to motivate families to become active participants in the management of their children's asthma. For families to participate in the interactive classes, time and commitment were required of them by our program. Although we believe that our program consisted of "need to know" information only, asking families in today's hectic world to attend 4 classes ( 1.5 hours weekly for 4 weeks) may be asking too much. Further investigation is needed to assess the impact of a modified and shorter program.

We believe that the most important feature of our educational program was the interaction that it fostered between participants in their respective smallgroup settings. In the written feedback we received, parents and children reported that they felt less isolated when dealing with asthma and believed that they benefited from the group-oriented experience. Having other parents share their experiences may be a powerful learning tool. It may have a greater positive impact on strategies for the management of asthma than passively listening to someone teaching the same material. Opportunities to question, problem-solve and engage in activities with others who share similar challenges may serve to promote empowerment. These hypotheses will need to be tested using qualitative analysis.

\section{Conclusions}

Our small-group, interactive educational program for children with asthma was found to be effective in significantly reducing the need for hospital-based emergency services. During the year after enrolment, children of families who participated in the educational program required fewer courses of oral corticosteroid therapy and their primary caregivers lost fewer workplace hours. Quality of life for the children and their families improved. Education about asthma, especially in a small-group, interactive format, is an important aspect of overall care for children with asthma.

This article has been peer reviewed.

Competing interests: None declared.

Contributors: Wade Watson was the primary investigator of the study. Wade Watson, Cathy Gillespie, Michelle Piwniuk and Allan Becker were involved in the conception and design of the study protocol. Nicola Thomas, Shauna Filuk and Judy McColm 
were involved in the acquisition of data. All of the authors were involved in the analysis and interpretation of the data. Wade Watson, Cathy Gillespie, Michelle Piwniuk and Allan Becker were involved in the drafting of the manuscript. All of the authors were involved in the critical revision of the manuscript and approved the final version submitted for publication.

Acknowledgement: We thank Mary Cheang for her assistance with statistical analysis.

Funding: Support for this study was provided by Manitoba Health, the Winnipeg Children's Hospital Foundation and unrestricted educational grants from AstraZeneca, Merck Frosst and GlaxoSmithKline.

\section{REFERENCES}

1. Sullivan SD, Weiss KB. Health economics of asthma and rhinitis. II. Assessing the value of interventions. J Allergy Clin Immunol 2001;107:203-10.

2. National Heart, Lung and Blood Institute. Guidelines for the diagnosis and management of asthma 1997. Bethesda (MD): National Institutes of Health; 1997 Publi no. 97-4051.

3. Boulet LP, Becker A, Bérubé D, et al. Canadian asthma consensus report, 1999. CMAJ 1999;161(Suppl 11):S1-62.

4. Becker A, Bérubé D, Chad Z, et al. Canadian pediatric asthma consensus guidelines, 2003 (updated to December 2004): introduction. CMAJ 2005;173(Suppl 6):S12-4.

5. Gebert N, Hümmelink R, Könning J, et al. Efficacy of a self-management program for childhood asthma - a prospective controlled study. Patient Educ Couns 1998;35:213-20

6. Cowie RL, Underwood MF, Little CB, et al. Asthma in adolescents: a randomized, controlled trial of an asthma program for adolescents and young adults with severe asthma. Can Respir J 2002;9:253-9.

7. Bonner S, Zimmerman BJ, Evans D, et al. An individualized intervention to improve asthma management among urban Latino and African-American families. J Asthma 2002;39:167-79.

8. Maslennikova GYA, Morosova ME, Salman NV, et al. Asthma education programme in Russia: educating patients. Patient Educ Couns 1998;33:113-27.

9. Madge P, McColl J, Patton J. Impact of a nurse-led home management training programme in children admitted to hospital with acute asthma: a randomized controlled study. Thorax 1997;52:223-8.

10. Harish Z, Bregante AC, Morgan C, et al. A comprehensive inner-city asthma program reduces hospital and emergency room utilization. Ann Allergy Asthma Immunol 2001;86:185-9.

11. Volsko TA. A pediatric asthma clinic pilot program reduces emergency department visits, hospitalizations and cost of care. Respir Care 1998;98:107-13.

12. Greineder DK, Loane KC, Parks P. A randomized controlled trial of a pediatric asthma outreach program. J Allergy Clin Immunol 1999;103:436-40.

13. Haby MM, Waters E, Robertson CF, et al. Interventions for educating children who have attended the emergency room for asthma [review]. Cochrane Database Syst Rev 2001;(1):CD001290.

14. Wolf FM, Guevara JP, Grum CM, et al. Educational interventions for asthma in children [review]. Cochrane Database Syst Rev 2002;(4):CD000326.

15. Hanson J. Parental self-efficacy and asthma self-management skills. J Soc Pediatra Nurs 1998;3:146-54

16. MacKeracher D. Making sense of adult learning. 2nd ed. Toronto (ON): University of Toronto Press; 2006.

17. Westberg J, Jason H. Fostering learning in small groups: a practical guide. New York (NY): Springer Publishing Company; 2004.

18. Halpern DF, Hakel MD. Applying the science of learning to the university and beyond: teaching for long-term retention and transfer. Change 2003;35:36-41.

19. Juniper EF, Guyatt GH, Feeny DH, et al. Measuring quality of life in children with asthma. Qual Life Res 1996;5:35-46.

20. Juniper EF, Guyatt GH, Feeny DH, et al. Measuring quality of life in the parents of children with asthma. Qual Life Res 1996;5:27-34.

21. Reilly MC, Zbrozek AS, Dukes EM. The validity and reproducibility of a work productivity and activity impairment instrument. Pharmacoeconomics 1993;4:353-65.

22. Watson WTA, Filuk-Enns SE, Piwniuk M, et al. Validation of workplace productivity and school productivity questionnaires in children with asthma [abstract]. $J$ Allergy Clin Immunol 1999;103:S231.

23. Ernst P, Fitzgerald JM, Spier S. Canadian Asthma Consensus Conference summary of recommendations. Can Respir J 1996;3:89-114.

24. Laforest L, Yin D, Kocevar VS, et al. Association between asthma control in children and loss of workdays by caregivers. Ann Allergy Asthma Immunol 2004; 93:265-71.

25. Liu C, Feekery C. Can asthma education improve clinical outcomes? An evaluation of a pediatric asthma education program. J Asthma 2001;38:269-78.

26. Detwiler DA, Boston LM, Verhulst SJ. Evaluation of an educational program for asthmatic children ages 4-8 and their parents. Respir Care 1994;39:204-12.

27. Horner SD. Using the Open Airways curriculum to improve self-care for third grade children with asthma. $J$ Sch Health 1998;68:329-33.

28. McCarthy MJ, Herbert R, Brimacombe M. Empowering parents through asthma education. Pediatr Nurs 2002;28:465-73.

29. Collins J. A programme to reinforce understanding: An educational programme for hospitalized children with asthma. Prof Nurse 1994;9:225-8.

30. Deaves DM. An assessment of the value of health education in the prevention of childhood asthma. J Adv Nurs 1993;18:354-63.

31. Lord A, St. Leger LH, Ridge DT, et al. The value of asthma camps for young people in Victoria. Contemp Nurse 2001;11:133-4

32. Taggart VS, Zuckerman AE, Sly RM, et al. You can control asthma: evaluation of an asthma education program for hospitalized inner-city children. Patient Educ Couns 1991;17:35-47.

33. Pérez MG, Feldman L, Caballero F. Effects of a self-management educational program for the control of childhood asthma. Patient Educ Couns 1999;36:47-55.

34. Matthews B, Dickinson A, Cram F. Establishment and evaluation of a preschool asthma programme: A pilot study. Nurs Prax N Z 1998;13:25-34.

35. Moe EL, Eisenberg JD, Vollmer WM, et al. Implementation of "Open Airways" as an educational intervention for children with asthma in an HMO. J Pediatr Health Care 1992;6:251-5.

36. Colland VT. Learning to cope with asthma: a behavioural self-management program for children. Patient Educ Couns 1993;22:141-52.

37. Persaud DI, Barnett SE, Weller SC, et al. An asthma self-management program for children, including instruction in peak flow monitoring by school nurses. J Asthma 1996;33:37-43.

38. Alaniz KL, Nordstrand J. Camp Superteens: an asthma education program for adolescents. MCN Am J Matern Child Nurs 1999;24:133-7.

39. Clark NM, Brown R, Joseph CLM, et al. Effects of a comprehensive school-based asthma program on symptoms, parent management, grades, and absenteeism. Chest 2004;125:1674-9.

40. Shah S, Peat JK, Mazurski EJ, et al. Effect of a peer led programme for asthma education in adolescents: cluster randomized controlled trial. BMJ 2001;322:583-5.

41. Forshee JD, Whalen EB, Hackel R, et al. The effectiveness of one-on-one nurse education on the outcomes of high-risk adult and pediatric patients with asthma. Manag Care Interface 1998;11:82-92.

42. Young NL, Foster AM, Parkin PC, et al. Assessing the efficacy of a school-based asthma education program for children: a pilot study. Can J Public Health 2001; 92:30-4.

43. Guendelman S, Meade K, Benson M, et al. Improving asthma outcomes and selfmanagement behaviors of inner-city children. Arch Pediatr Adolesc Med 2002; 156:114-20.

44. Ronchetti R, Indinnimeo L, Bonci E, et al.; Italian Study Group on Asthma SelfManagement Programmes. Asthma self-management programmes in a population of Italian children: a multicentric study. Eur Respir J 1997;10:1248-53.

45. Kelly CS, Morrow AL, Shults J, et al. Outcomes evaluation of a comprehensive intervention program for asthmatic children enrolled in medicaid. Pediatrics 2000; $105: 1029-35$

46. Wesseldine LJ, McCarthy P, Silverman M. Structured discharge procedure for children admitted to hospital with acute asthma: a randomized controlled trial of nursing practice. Arch Dis Child 1999;80:110-4.

47. MeGhan SL, Wong E, Jhangri GS, et al. Evaluation of an education program for elementary school children with asthma. J Asthma 2003;40:523-33.

48. Butz A, Pham L, Lewis L, et al. Rural children with asthma: impact of a parent and child asthma education program. J Asthma 2005;42:813-21.

49. Butz AM, Tsoukleris MG, Donithan M, et al. Effectiveness of nebulizer use-targeted asthma education on underserved children with asthma. Arch Pediatr Adolesc Med 2006;160:622-8.

50. Gerald LB, Redden D, Wittich AR, et al. Outcomes for a comprehensive schoolbased asthma management program. J Sch Health 2006;76:291-6.

51. Cicutto L, Murphy S, Coutts D, et al. Breaking the access barrier: Evaluating an asthma center's efforts to provide education to children with asthma in schools. Chest 2005; 128:1928-35.

52. Patterson EE, Brennan MP, Linskey KM, et al. A cluster randomised intervention trial of asthma clubs to improve quality of life in primary school children: The school care and asthma management project (SCAMP). Arch Dis Child 2005;90: 786-91.

53. Walders N, Kercsmar C, Schluchter M, et al. An interdisciplinary intervention for undertreated pediatric asthma. Chest 2006;129:292-9.

54. Sockrider MM, Abramson S, Brooks E, et al. Delivering tailored asthma family education in a pediatric emergency department setting: a pilot study. Pediatric 2006;117:S135-44.

55. Joseph CLM, Peterson E, Havstad S, et al. A web-based, tailored asthma management program for urban African-American high school students. Am J Respir Crit Care Med 2007; 175:888-95

Correspondence to: Dr. Wade Watson, IWK Health Centre, 5850/5980 University Ave., PO Bvox 9700, Halifax NS B3K 6R8; fax 902 470-7308; wade.watson@iwk.nshealth.ca 